\title{
The role of digital simulation in assessing and reassessing the potential of complex coal deposits
}

\author{
Vladimir Gavrilov ${ }^{1,2}$, Evgenii Khoiutanov ${ }^{2 *}$, Natal'ya Nemova $^{1}$ and Dmitrij Son $^{3}$ \\ ${ }^{1}$ N. A. Chinakal Institute of Mining, Siberian Branch, Russian Academy of Sciences, Laboratory of \\ Open-pit Mining, 630091, Novosibirsk, Russia, gvlugorsk@mail.ru \\ ${ }^{2}$ Chersky Institute of Mining of the North, Siberian Branch, Russian Academy of Sciences, \\ Laboratory of the Problems of Rational Use of Mineral Resources, 677980, Yakutsk, Russia \\ ${ }^{3}$ Coal Department JSC «ArselorMittalTemirtau», Department of Geoforecast and Geomechanics, \\ 101200, Saran', Kazakhstan
}

\begin{abstract}
The article addresses the increasing complexity of mined or prospective coal deposits. The paper analyses the role of digital simulation in operation assessment and reassessment of the potential of complex in structure coal deposits for more accurate understanding their investment attractiveness, reliability of knowledge on quantity and quality of the reserves. The article stresses the objective need to take into account the realities of the VUKA-world, when companies have to react rapidly to changing of external conditions by adapting organizational and technological measures as much as possible to the constantly overestimated potential of the raw material base. It is of note that reserves should be assessed in accordance with international requirements in the light of the increasing number of parameters for management. The complexity of the structure, the geomechanical heterogeneity of the rock mass, the mineral content of the impurities in the coal, its caking capacity, oxidation and enrichment are taken into account in the estimation. The paper presents the measures to increase the level of utilization of geological potential through the application of selective mining and the control of different quality coal streams in preparation for enrichment and during primary processing.
\end{abstract}

Keywords. Coal, deposit, complex structure, quality, estimation, digital model, uncertainty

\section{Introduction}

Development of coal deposits often takes place in extreme climatic and geological conditions [1, 2]. These conditions are constantly deteriorating as a result of the exploitation of relatively simple deposits with relatively low depths in areas with developed transport and energy infrastructure [3]. It is more relevant for deposits with scarce coking coal. The Apsatskiy, Elginskiy, Elegestskiy, Chulmakanskiy, Kadykchanskiy and other deposits characterize by: thinning, splitting, disturbance of coal beds, inconsistency of their

* Corresponding author: khoiutanov@,igds.ysn.ru 
capacities and angles of incidence, the presence of different brands and grades of coal within the same seam, block; high variability and non-additivity of consumables of raw materials in reserves; cluster distribution of useful and harmful components; other natural and technological factors.

The consequence of this situation is the inevitable complication and rise in cost of all processes of long-term and multi-stage development of deposits. The real and potential risks of making irrational technical, technological, organizational and economic decisions increase dramatically. All this leads to toughening requirements for the level of decisions made at all stages of exploration of deposits, their assessment, design, construction of companies, development and processing of reserves, reclamation of disturbed lands.

An increase in the level of scientific and practical substantiation of the opinions and conclusions of experts can be achieved on the basis of the maximum possible understanding in terms of completeness and accuracy at the current time of all visible and hidden features and capabilities of the fields themselves, as well as various business initiatives implemented during their development. In such a situation, the improvement of work on a technologically efficient, economically viable and environmentally acceptable level of development of coal deposits should be carried out taking into account the following approaches [4]. Approved reserves are a probabilistic, to some extent inaccurate and unreliable geological resource that requires continuous additional study during prospecting and development. Increased efficiency is achieved through the rational combination of various technologies, their parameters, organizational measures and techniques. All links in the supply chain are treated as a single dynamic system "georesource - consumer», operating in a coordinated manner in a difficult competitive external environment.

The analysis shows that the theory and practice of prospecting, simulation, estimating and refining reserves generally do not fully take into account all the important and minor features of the mineral raw material base, the ever-increasing potential of digital technologies for comprehensive assessment and rapid reassessment [3, 5-8]. This, in turn, necessitates a more detailed consideration of the situation described.

\section{Theory}

Direct use of mining and geological information (contours and boundaries of deposits, temporary and permanent restrictions (conditions), balance reserves, content of harmful and useful components, etc.) accumulated over many years, without appropriate analysis and rapid reassessment according to modern criteria, is difficult. Adaptation to current or prospective market conditions often requires. For example, in the Southern Yakutia Integrated Development Program, many projects were delayed or frozen because of the reason given and the sharp fluctuations in the markets for coal, uranium and iron [3].

The active entry of Russian and Kazakh coal companies into foreign markets has contributed to a certain extent to an increase in the depth of study of the real composition of coking coals and their subsequent differentiation into technological types and grades. The approach to studying the quality of the hard coking coal of Nerjungrinskiy deposit in reserves and process flows, currently being developed and replicated in South Yakutia, can serve as an example $[3,9,10]$. After detailed exploration, additional operational exploration is carried out, ahead of the testing of reserves, their mapping by marks with a stage-bystage thickening of the well grid and increasing the accuracy of testing. Further, face sampling, input and output quality control of raw coal at the warehouses of the open pit, the processing plant, concentrate and dressing products in the flows at the factory and finished product warehouses, at the points of transfer of ownership (ports, railway stations, consumers) are performed.

The main results of the labor-intensive work carried out by the companies are: the 
established extension and increasing complexity of the boundaries of the areas of the unoxidized, oxidized and partially oxidized coals; adjustment of the reserves structure, with separation of additional technological groups of coal; expansion of the range and variability of reservoir capacity and its bundles, ash content and structure, sintering and coking capacity and coal enrichment; introduction of new methods of coal quality assessment. Similar examples can be found for other complex and heterogeneous deposits.

The method used in Russia to establish the conditions for calculating and estimating coal reserves is not sufficiently reliable because of the small number of geological and mining parameters involved in the accounting of the deposit and the parameters for the exploitation of reserves, geotechnology and its economic benefits [6]. The experience of Russian commodity companies in conducting an IPO using the JORC Code for economic reassessment shows that the undervaluation of their mineral base (up to $30 \%$ ) reduces the investment attractiveness of companies' projects [5]. The new assessment by the experts is based on an analysis of the mining experience, which is often not generalized and presented at the coal mines and the cuts. In order to obtain a better understanding of the georesource, much attention is paid to the reliability of the understanding of the quality of coal, which can be improved by comparing the geological survey data with the results of coal testing in mining operations.

The world economy, including the mining sector of nearly every country, is being forced to move from a relatively steady, predictable, ordinary, definite (SPOD-world) to a volatility, uncertainty, complexity, ambiguity development environment (VUCA-world) [11]. Continuous changes in the external environment in relation to companies (deposits as objects for efficient development and a highly competitive and difficult to predict market for mineral raw materials) require the management of mines, open-pit mines and associated processing plants to respond as quickly and flexibly as possible to transform and adapt their internal state [12]. Such work is carried out on the basis of variant simulation of various processes, including the assessment and reassessment of the potential of deposits and the use of the constantly expanding capabilities of information technologies.

More advanced oil and gas industry expands the application of the «digital field» concept. «Digital field» means the evolution and integration of drilling, exploration, digital process management and production technologies with modern communication technologies $[13,14]$, collection, processing, analysis and optimal use of the full range of geological, geophysical, geomechanical, technological, economic data. The introduction into the theory and practice of mining of coal deposits the approaches formed and developed within the framework of this concept helps for better structuring and optimization of the activities of the companies in the coal exploration, mining and enrichment chain.

This is achieved by creating the most reliable geological, geomechanical and technological models of deposits (sites, strata); integrating operations (excavation and transport, quality management and loss of raw materials) management of different mining scenarios. An integrated approach to the mining process achieves a system-wide state in which the actual extraction of raw materials in specified quantities with the required market quality level and costs are as close as possible to the plan. The plan, in turn, can evolve dynamically over time according to specific circumstances.

\section{Results and discussion}

To analyze the structure of coal deposits, study their internal structure, 3D simulation, mining and geological information systems Mineframe, Micromine, ArcGIS are used, specially developed methodological techniques, standard and new methods of data processing. Their use in a complex made it possible to carry out, with varying degrees of 
detail, the preparation of a number of decisions aimed at increasing the level of realization of the potential of the coal reserves of a number of coal deposits laid down by nature. It is based on more accurate assessments of the level of compliance with the best available technologies, principles of organization and management.

Despite the high impact of the market environment, the potential of a complex and heterogeneous deposit determines the competitiveness of the mining company. Deposits and companies involved in their development are unique natural and technological complexes with a large number of factor groups. They are intricately interconnected and constitute a significant, time-growing body of information that should be used as efficiently as possible. There are many different conditions for the exploration, extraction and processing of minerals not only for each deposit as a whole but also for its blocks, aquifers and mining sites. Among the many, there are unique combinations of just a few factors that decisively determine the efficiency and safety of development. But, as practice shows, there can be hundreds of combinations of such factors in a large and complex deposit, which must be taken into account when planning and conducting exploration and mining operations. The adaptation of personnel, techniques and technologies to the constant changes associated with the georesource is hampered by a lack of predictability and accuracy in estimating the values of the main geological and technological variables [3].

The proposed approach to the differentiation of ash of the coal in complex structural deposit (like the Elginskiy) and the developed methodology for the assessment of natural and technological dilution take into account the characteristics of coal formation, structure and forms of the inorganic substance found in coal, increased understanding of the mechanisms of fuel quality change from reserves to coal mining and coal enrichment flows [15]. The resulting estimates of the differences in the ash content of coal in the surface and subsurface parts of a number of seams provided the basis for justifying the need for their gross or selective processing to produce more homogeneous coal flows. The assessment of the prospects for simple (by area) and complex (by capacity) selective coal excavation schemes of different quality shows that it would be useful to take into account not only the ash reduction potential of individual rock layers, but also the structural potential, spatial distribution and total capacity of all intercalated beds. It is recommended that seams (sites) with stable differences in ash content and/or structure should be exploited with subbench and forming of separate coal streams of different ash and enrichment. The height this subbench has to coincide with the limits of these zones.

A number of issues need to be addresses in the simulation of complex coal seams and the various types of enclosing rocks using the above systems. These include an adequate description of multiple conversions where the exploration well crosses several alternating lithological layers. In simulation, the interpolation and automatic surface construction algorithms in the programs cannot identify them to determine to which layer a particular intersection should be attributed. As a result, average images are produced (fig. 1). Requirements for the grid density of the wells to obtain an adequate result are increased.

Layering also complicates stratigraphic simulation. Due to the complexity of stratigraphic hierarchy, the correlation between the layers has to be done manually, indicating which layer, dipped with a well, forms a body with the same layer on the other well. The automatic correlation of layers with the types of contacting rocks during multiple conversions, even in small areas, leads to the construction of averaged (smoothed) surfaces. With several close layers, one common surface is constructed, often even "not lying" on the layers themselves (fig. 1, 2). The above-mentioned makes it more difficult to use the primary geological and surveying data of interval tests of wells integrated in the deposits databases in order to obtain new results. This in turn implies the need to expand the range of methods used for spatial-temporal analysis of the whole range of geological and geodetic variables. 


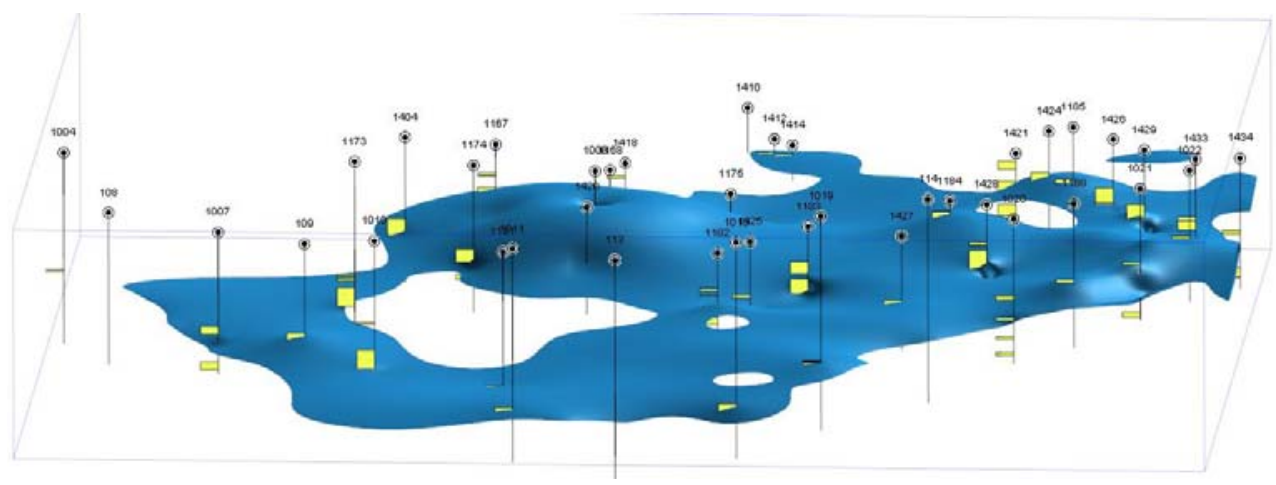

Fig.1. Coal deposit rock layer model

The results of the proposed information approach with rapid reassessment of reserves are expanding our understanding of the natural and economic potential of coal deposits. The potential for more precise spatial differentiation of coal by types, grades and technological groups with different market appeal raises the question of whether coal quality management is appropriate. Summing the potential of the separately assessed areas, beds, taking into account the complexity of the structure, geomechanical and geophysical of the rock mass, mineral impurities in coal, its stratification and enrichment should contribute to the overall increase of investment attractiveness of the deposit. Various digital technologies are a unifying tool for such an approach.

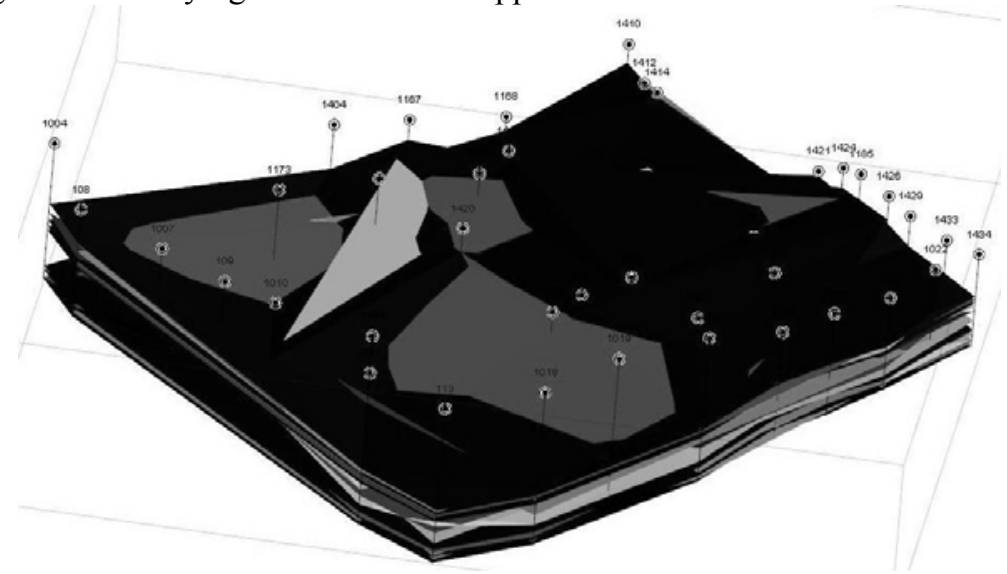

Fig. 2. Model of different lithology layers of rocks

Research into the theoretical and practical aspects of the assessment of coal deposits suggests their further development. Among the priorities for solving the problems follows: refined explanation of the reasons of incomplete conformity of the model to real natural objects; meaning and studying potential of use of the concept of «digital field» as systems for the intelligent management of operations involving the exploration of coal georesources, their rational extraction from the subsoil and their primary processing; the interrelated development and joint use of geological, geophysical, geomechanical and geotechnological models, taking into account the possibilities of linear and non-linear interpolation methods for estimating rock types, coal properties in reserves and process flows under integrated quality management. 


\section{Conclusions}

The objective need to develop complex coal deposits in terms of structure, conditions and quality requires improved certainty, accuracy and reliability of knowledge of their geological (natural) potential.

The goal of the efficient technological transformation of coal into products determine the desirability of a deeper and more precise differentiation of the changing potential of the deposits over time, based on the wide application of digital technologies and variety of assessments.

The adoption on this basis of rational decisions on gross, selective and combined mining of reserves of deposits, including the methods considered, provides the formation of technological flows of coal that are more homogeneous in properties, fully adapted to the conditions of its further processing.

The proposed information approach to the assessment and reassessment of the potential of coal deposits contributes to the broadening of the understanding of their natural and economic nature and the increasing investment attractiveness.

\section{References}

1. B. M. Vorob'ev, Ugol' mira. T. 3 Ugol' Evrazii (Gornaya kniga, 2013)

2. Coal Base of Russia. Vol. V. Book 2: Coal basins and deposits of the Russian Far East (Geoinformmark, 1999)

3. S. A. Batugin, V. S. Litvintsev, V. I. Cheskidov, Open-pit mining geotechnologies in deposits with complex mining and geological conditions (Geo, 2013)

4. V. L. Gavrilov, E. A. Khoutanov, A. N. Petrov, Bulletin of ZabGU, 10, 12-20 (2018)

5. S. V. Shaklein, A. A. Rozhkov, T. B. Rogova, Ugol, 1, 47-51 (2015)

6. V. V. Agafonov, Ugol, 4, 82-85 (2019)

7. R. S. Panov, B. K. Mikhailov, S. A. Kimelman, Mineral Resources of Russia. Economics and management, 4, 34-38 (2018)

8. V. Cherepanov, Globus, 2, 58-62 (2020)

9. V. N. Mashir, L. D. Luhtina, Ugol, 6, 46-48 (1987)

10. E. V. Frejdina, A. A. Botvinnik, A. N. Dvornikova, Systematic Coal Quality Management in the Open Mining of Siberia (Nauka, 2019)

11. S. R. Islamov, Ugol, 9, 26-32 (2018)

12. V. L. Gavrilov, S. M. Tkach, MIAB, 11(37), 112 - 121 (2019)

13. A. I. Vlasov, A. F. Mozhchil, PRONEFT'. Professionally about oil, 3, 68-74 (2018)

14. Digital-Oilfield, http://itpss.ru/docs/pos-materials/201710-Digital-Oilfield-Designand-Implementation.pdf (2017)

15. E. A. Khoyutanov, V. L. Gavrilov, Journal of Mining Science, 55(3), 399-406 (2019) 